Elsevier required licence: ( 2019 . This manuscript version is made available under the CC-BY-NC-ND 4.0 license http://creativecommons.org/licenses/by-nc-nd/4.0/

The definitive publisher version is available online at https://doi.org/10.1016/j.jvoice.2019.06.017 


\section{Functional dysphonia: A clear need for differential diagnosis.}

Commentary on "Lorazepam-Assisted Interview in a Resistant Case of Functional Dysphonia" Modak et al., (2019) J Voice. Jan 28. pii: S0892-1997(18)30451-X. doi: 10.1016/j.jvoice.2019.01.002.

In their recent article "Lorazepam-Assisted Interview in a Resistant Case of Functional Dysphonia", Modak et al. (2019) describe the use of Lorazepam in drug-assisted interviews for the treatment of a resistant case of functional dysphonia.

Although we are pleased to see further research into the treatment of resistant functional dysphonia, we have serious concerns regarding the diagnosis of functional dysphonia in the case presented. The article describes a 40-year-old gentleman with sudden onset of articulation difficulties, being "unable to make movements of the tongue while speaking although power and range of movement were normal". The authors report that the gentleman was "able to produce sounds but had lost the ability to modulate sounds into meaningful words".

In viewing the excellent supplemental case videos accompanying the article, the symptoms evident were limited movement of the articulators with a relatively fixed open jaw position, abnormal fixed tongue positioning with the tongue held anteriorly and on the floor of the mouth throughout speech production, slow rate and monotonous speech quality with equal and excess stress on words. Post treatment, normal tongue, lip and jaw movement is observed, with the speech remaining monotonous with equal and excess stress. Normal phonation is present throughout the pre-treatment and posttreatment video recordings suggesting no disruption to vocal fold movement or vocal function.

While differential diagnosis of organic versus functional neurological disorder was discussed by the authors, we would respectfully suggest that this case required careful attention to the differential diagnosis between a functional/psychogenic dysphonia (see Baker, 2016) over functional/psychogenic speech disorder (see Duffy, 2016). Clearly the symptoms we observed from the videos as well as those described by the authors in the article, were of marked alterations to articulation rather than phonation. The article therefore describes the treatment of a functional/psychogenic speech disorder and as such, the title of the article is misleading.

We feel that the article by Modak et al. 2019 highlights the need for clear criteria that enables differential diagnosis of functional-psychogenic dysphonia and the need for authors to include transparent inclusion and exclusion criteria based on these criteria in future studies on functional voice disorders.

Baker, J. (2016) 'Functional voice disorders: clinical presentations and differential diagnosis', in Hallett, M., Stone, J., and Carson, A. (eds) Functional Neurologic Disorders, Volume 139 of the Handbook of Clinical Neurology series. Elsevier, pp. 389-406.

Duffy, J. R. (2016) 'Functional speech disorders: clinical manifestations, diagnosis, and management', in Hallett, M., Stone, J., and Carson, A. (eds) Functional Neurologic Disorders, Volume 139 of the Handbook of Clinical Neurology series. Elsevier, pp. 379-388. 